\title{
Question -Response in Online Synchronous Videoconferencing Class
}

\author{
Obaida Chaqmaqchee \\ Department of English, Faculty of Modern Languages and Communication \\ Universiti Putra Malaysia, Malaysia \\ Shamala Paramasivam (Corresponding author) \\ Department of English, Faculty of Modern Languages and Communication \\ Universiti Putra Malaysia, Malaysia \\ Tel: 6-12-235-5952Ｅ-mail: shamala@upm.edu.my
}

Received: October 30, 2021 Accepted: November 29, 2021 Published: December 7, 2021

doi:10.5296/ijl.v13i6.19133

URL: https://doi.org/10.5296/ijl.v13i6.19133

\begin{abstract}
With recent developments in technology and its massive impact on the education field, videoconferencing has emerged as an effective teaching learning tool in the language classroom. It is mainly a means of communication to overcome the impediments of geographical distance and separation. However, despite the successful implementation of this technology, it has been stated that using videoconferencing for online teaching is problematic. Videoconferencing impedes instructor-learner interaction and is unable to replace the traditional face-to-face classroom. To understand online interaction from a sociocultural standpoint, this study examined the characteristics of instructor questions in terms of cognitive level so as to investigate if instructor question can function as a stimulus for interaction in the online classroom. The results show that cognitive level of instructor question can function as an effective factor to promote online classroom interaction. Conclusions and implications are drawn at the end of this paper to help understand interaction in online learning.
\end{abstract}

Keywords: Instructor question, Cognitive level, Student response, Videoconferencing, Online interaction, Online synchronous classroom 


\section{Introduction}

The availability and accessibility of technology along with its rapid development have led to massive growth in online education within a short time. Technology is implemented as an essential tool for communication between students and instructors to eliminate the current impediments represented by geographical distance. Currently, most academic institutions include technological means for teaching and learning that incorporate online collaboration in addition to face-to-face classes (Banna et al., 2015; Kauffman, 2015). Through online collaborative learning, students receive authentic and reliable linguistic input, produce output, and receive feedback, (Lee, 2007) especially when they interact with native speakers of the target language (Durairaj \& Umar, 2015).

The literature shows that the traditional and online teaching and learning contexts are different (Herring, 2004). The traditional teaching and learning context is preferred and found more effective than online context solely because of the face-to-face teaching and learning interactions that take place in real time (Abrami et al., 2011). A point to note is that the online synchronous mode of interaction although involves face-to-face interaction through the online medium does not automatically result in efficient and constructive interaction (Mirza, 2014). Thus, to successfully adopt online educational tools, it is important to provide appropriate pedagogical practices that suit this online-based instruction (Terras, 2017). As a result, this field is in need of more heuristic research to illuminate the path for instructors and provide more reliable, supportive, sustainable, and interactive online learning environments.

This study investigated the impact of different cognitive load with regard to teacher question and learner response in the online language learning classroom. It is grounded within a sociocultural perspective as this perspective supports interaction and learning; within this perspective, language is viewed as a cultural and psychological tool for learning including online learning (Drummond et al., 2008).

\subsection{Interaction in Online Learning Platforms}

Swain (1985) asserts that when students are pushed to produce the target language, they have the chance to improve on the language. Through different communicative tools, technology offers interactive opportunities to interact with native speakers as a fundamental means to augment the language learning process (Zhou et al., 2020; O'Rourke \& Stickler, 2017; Greene, 2003). However, online interaction has now become a challenge, and most of the studies try to offer a natural interaction similar to the traditional classroom (Covelli, 2017). The Medium Naturalness Theory (MNT) states that a reduction in the degree of a given medium's naturalness may lead to a decline in learning effectiveness as a result of the increased cognitive load imposed on the learner, higher ambiguity of the conveyed message, and lower psychological arousal. In contrast, a communication channel that has a higher degree of medium naturalness can encourage more effective communication, which might lead to better interaction. Hence, effective e-learning should aim to reach the highest degree of naturalness as in traditional face-to-face interactions (Weiser et al., 2018; Sun \& Cheng, 2007).

The literature shows that communicating via media, that supports several input channels, is 
usually associated with higher cognitive load, higher ambiguity and, consequently, decreased quality of learning processes and outcomes (Caspi \& Blau, 2008; Kock, 2005). Several studies have investigated interaction in online language learning and focused on the nature of the verbal interaction taking place and how it may impact learning outcomes (Palomeque \& Pujolà, 2018). The main tenet behind these studies is that communication via computer is different from traditional face-to-face communication.

Therefore, different studies have developed different assessments of the verbal interaction taking place in the language classroom that focuses on either the quality or quantity of participation (Altıner, 2015; Ertmer, Ertmer and Sadaf, 2011). The quantity account of interaction has been assessed by using different tools such as duration of participation (Shantha \& Mekala, 2018), or words per sentence/turn (Wright, 2016; Qashoa, 2013; Farahian \& Rezaee, 2012) when using the target language. The quality of participation has been assessed by tools such as syntactic complexity in students' participation measured through T-unit (Inoue \& Zhang, 2011; Bygate, Skehan, \& Swain, 2001), C-unit (Wright, 2016; Lindenmeyer, 1990; Mehnert, 1998), and number of clause per chosen unit (Iwashita et al., 2001; Robinson, 2007). In addition to length and syntactic complexity, other indicators for participation are accuracy (Thai \& Boers, 2016) and fluency (Ahmed \& Alamin, 2014; Portocarrero et al., 2007) in students' production. In online-based studies, interaction is often holistically assessed based on the amount of classroom participation or quantitatively based on the number of words per participation (Aydemir et al., 2016; Weiser et al., 2018).

In sum, the literature shows that online interaction has become a challenge for teachers who have to implement interactional approaches in online classrooms. More studies are needed to investigate the online learning mode so that we have an understanding of interactive online practices between teachers and learners on online learning platforms. The current study is an attempt to this end.

\subsection{Question as a Pedagogical Device}

In the classroom, questions serve various functions such as focusing attention, exerting disciplinary control, getting feedback, and encouraging students' participation (Brock, 1986; Gall, 1970; Wu, 1993; AbuBakar et al., 2021). Questions in the classroom have garnered much interest in discourse studies. Such studies have looked at the didactic function of questions and the relationship between different question types and learning outcomes (Vuleta \& Martinović, 2019; AbuBakar et al., 2021).

In a speaking classroom, where the pushed output is an objective, questions are considered as a key teaching method that can be used to achieve the objective of the classroom. Therefore, questions have been classified widely in the literature. Among the criteria that are used to categorize questions is Bloom's Cognitive Levels (BCLs)(Fei et al., 2003). In his effort to classify thinking behaviors, Benjamin Bloom identified three domains: cognitive (mental skills), affective (growth in feelings or emotional areas) and psychomotor (manual or physical skills).

The MNT states that increasing the cognitive effort that is associated with any unnatural 
medium may be referred to as extraneous load (Sweller et al., 1998; Van \& Sweller, 2005). Extraneous load is caused by the format of instruction as opposed to intrinsic load which is associated with the learning task itself. According to the Communicative Language Teaching (CLT) method, a higher extraneous load interferes with learning (Sweller, 1994).

To conclude, questions have the potential to increase learner interactivity (Levin \& Nolan, 2004). The literature shows that designing and improving interactive online classroom does not happen by accident. Glance et al. (2013) state that an interactive online class requires clear, planned, and well-crafted questions suitable for this environment. Therefore, effective questioning strategy prompts interaction between instructor and learners and immediately enhances classroom interactivity (Bernstein, 2013; Goossen, 2002).

As no study has investigated the characteristics of instructor questions in EFL online classrooms, this study aims to measure the impact of instructor questions on students' interaction. Interaction is measured in terms of students' participation, fluency, complexity and cognitive level of students' responses to instructor questions.

The specific research questions of the study are:

1.What types of questions are asked by instructors in an online synchronous videoconferencing classroom?

2.How do instructor questions impact classroom interaction in an online synchronous videoconferencing classroom?

3.How do instructor questions impact student responses in an online synchronous videoconferencing classroom?

\section{Method}

\subsection{Research Design}

The study is qualitative descriptive in nature. This design is used to deal with the collection, analysis, and interpretation of natural and authentic data to gain insight into the particular phenomenon under investigation.

\subsection{Research Site and Sample}

Two instructors were involved in the study. They were native speakers of English; one was a female from the U.K and the other was a male from the U.S. Both were qualified with master's degrees in TESOL with more than five years of experience in teaching English as a foreign language.

The students were 20 EFL (12 male and 8 female) intermediate level students aged between 23-26. They were Arab and Chinese international students and they registered for English course in preparation for their academic study as masters' students. This foundation course teaches students the four language skills (reading, writing, listening, and speaking) in four separate classes.

The data was collected in the speaking class which the students attend weekly in classes 
delivered online via Zoom. The data was collected from a privately-owned institute in Kuala Lumpur, Malaysia. Permission was granted by the institute concerned and consent forms were obtained from the participants of the study, both instructors and students.

\subsection{Data Collection}

Data collection involved audio-recording the classroom interaction between the instructors and students. Five online videoconferencing classroom sessions were recorded using audio recorders. Each session lasted from 30 to 45 minutes. The data for this study comprise 160 minutes of classroom interaction.

\subsection{Data Analysis}

The recordings were carefully transcribed orthographically using an intelligent verbatim transcription. All parts that were not relevant for the study, that do not contribute to meaning or comprehension of the interaction were excluded. The whole data were analyzed for instructor questions and subsequent student responses. Data analysis involved two stages.

\subsubsection{Data Analysis Stage 1: Instructor Question}

The first stage of analysis involved instructor questions. Indirect questions were excluded from the study; the study focused on direct questions as they are considered an important instructional tool in any language classroom (Parker \& Hurry, 2007). Direct questions by instructors were classified following the Newcomb-Trefz model (1983) of questions into two cognitive levels: high-order thinking skills (HOTS) and low-order thinking skills (LOTS) (see Figure 1).

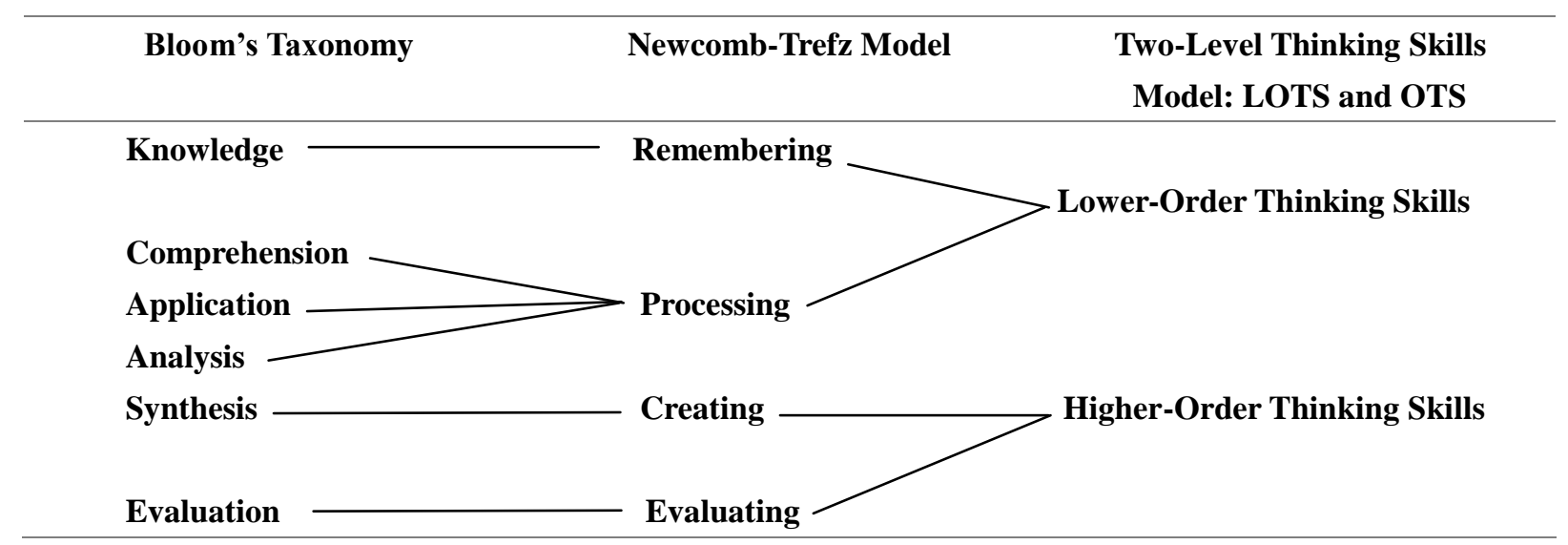

Figure 1. The Newcomb-Trefz model

Lower-level questions are those at the knowledge, comprehension, and simple application levels of the taxonomy. Higher-level questions are those requiring complex application (e.g., analysis, synthesis, and evaluation skills). The frequency of each type of question was counted to find its impact on classroom participation and interaction in the next stage, as explained below.

\subsubsection{Data Analysis Stage 2: Student Response}

The second stage of analysis involved student responses. Their responses were considered 
only for the turns immediately following instructors' questions. For series of responses from two or more students following an instructor's question, each response was considered as an answer paired with the question that initiated the interaction.

To determine the impact of each question, classroom interaction was quantified and classified by using different benchmarks. First, the number of responses paired to each question were counted to find the type of question that motivated students to interact with their instructors. Second, the impact of each question on students' thinking levels was determined by applying The Newcomb-Trefz model on students' responses. Each student response was assessed in terms of fluency and complexity. Student responses were analysed at the word and sentence level per turn. In terms of fluency, student responses were examined by summing up the number of words per answer for each response as a quantitative indicator. Cole \& Williams' (1973) classification (see Table 1) was then used as a benchmark to distinguish between three types of responses by length. For instance, a student's response like " ${ }^{1}$ pop ${ }^{2}$ music ${ }^{3}$ can ${ }^{4}$ make ${ }^{5}$ me ${ }^{6}$ relax ${ }^{7}$ of ${ }^{8}$ my ${ }^{9}$ study" was coded as a response with 9 words and classified at the second level. Whilst the response, " ${ }^{1} \mathrm{My}{ }^{2}$ close ${ }^{3}$ friends ${ }^{4}$ usually ${ }^{5}$ talk ${ }^{6}$ with ${ }^{7}$ me ${ }^{8}$ about ${ }^{9}$ their ${ }^{10}$ beautiful ${ }^{11}$ and ${ }^{12}$ healthy ${ }^{13}$ lifestyle ${ }^{14}$ in ${ }^{15}$ their ${ }^{16}$ country", was coded as 14 words and categorized at the third level.

Table 1. Observation guide for classifying student responses according to length and syntactic complexity (Adopted from Cole and Williams, 1973)

\begin{tabular}{ll}
\hline \multirow{2}{*}{ Length of response } & \multicolumn{1}{c}{ Student response } \\
\cline { 2 - 2 } & One to three word(s) \\
\cline { 2 - 2 } & Four to nine words \\
\hline $\begin{array}{l}\text { Complexity of } \\
\text { response }\end{array}$ & Word or phrase (incomplete sentence) \\
\cline { 2 - 2 } & Simple sentence \\
\cline { 2 - 2 } & Complex, compound, and multi-sentence \\
\hline
\end{tabular}

The complexity of the response was examined to provide a qualitative indicator. This was also done by using Cole \& Williams (1973) classification for responses (See Table 1). For example, the following response was analysed at the sentence level to find the type and number of meaningful sentences per turn: ${ }^{1}$ [when I feel bored I listen to pop music] ${ }^{2}$ [pop music can help me forget about my study and my life] ${ }^{3}$ [Taylor is my preferred pop-singer], and then classified as a complex answer at the third level in terms of syntactic complexity. Whilst the student response, [my close friends usually talk with me about their beautiful and healthy lifestyle ${ }^{i} n$ their country], was coded as one simple sentence and categorized at the second level of complexity. 


\section{1) Macrothink}

\section{Results}

\subsection{Frequency of Instructor Question}

The study showed that the instructors used both high and low cognitive level questions. The instructors asked 93 direct questions in the five sessions. The instructors asked approximately one question in each minute and a half. Out of 93 questions, 58 questions were of high cognitive level which asks students to create and evaluate information with a high cognitive load. In contrast, the instructors asked 35 questions of low cognitive level that require students to recall and process information with low cognitive load.

\subsection{Classroom Interaction}

Classroom interaction was linked and analysed by looking into the number of responses paired to each question, cognitive level, fluency, and complexity in students' responses. The findings are presented in the following sections.

\subsubsection{Instructor Question and Classroom Participation}

According to our study, questions with high cognitive level increased the whole classroom participation. In contrast, low cognitive level questions did not motivate students' participation.

The data showed that each question with a high cognitive level was answered by one or more student(s). The instructors asked 58 questions that were of high cognitive level and collected 103 responses from the students. This means that each question was answered by one or more than one student. In contrast, the instructors asked 35 questions that were of low cognitive level and collected 35 responses (see Figure 2); each question was answered by one student to which the question was assigned. Low cognitive level questions did not motivate the rest of the class to answer the same question voluntarily.

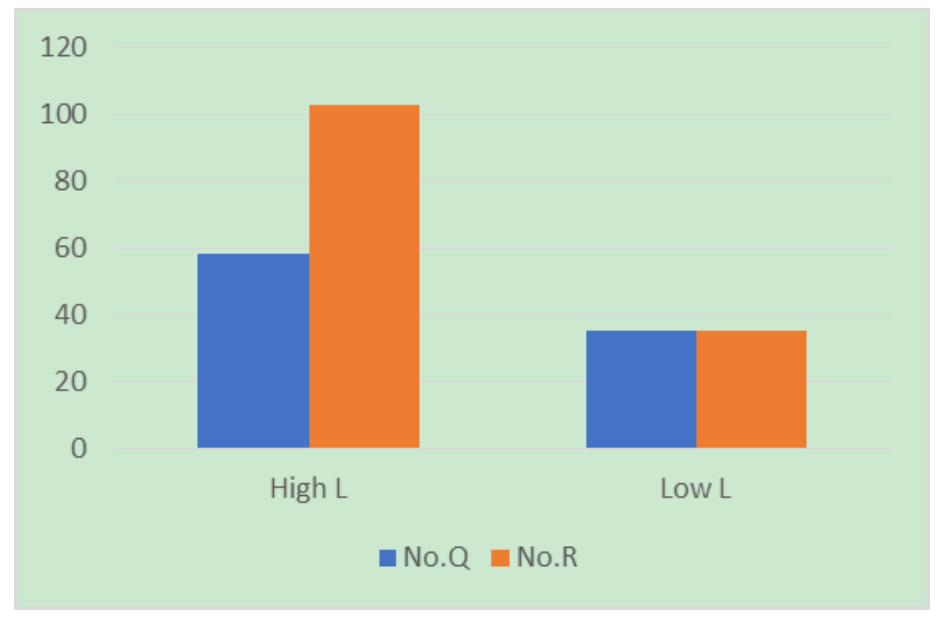

Figure 2. Instructor questions and classroom participation

\subsubsection{Instructor Questions and Students' Thinking Level}

Students' responses were analysed to find whether they correspond to the cognitive levels of 


\section{Al Macrothink}

International Journal of Linguistics

ISSN 1948-5425

2021, Vol. 13, No. 6

the assigned questions. Most of the questions triggered the anticipated cognitive level in students' answers; their answers corresponded to the same cognitive level of the question.

The instructors asked 58 questions that were of high thinking level. Consequently, they collected 103 responses, with 93 at high cognitive levels and 10 responses with low cognitive levels. Some questions that were of high cognitive levels collected low cognitive responses. On the other hand, all of the low cognitive questions collected low cognitive responses. The instructors asked 35 questions that were of low cognitive levels and collected 35 responses that were of low cognitive level.

\subsubsection{Instructor Questions and Student Fluency}

The fluency of student responses was analysed by summing up the number of words in students' responses and then classifying the responses using Cole and Williams' (1973) classification of responses. The results show that questions that were of high cognitive level have a negative impact on students' fluency. Students' answers were consistently short following high cognitive level questions. The 58 questions that were of high cognitive level, generated 103 responses with a mean of 9.8 words per question. Most of the responses were classified at the second and first levels. In contrast, low cognitive questions generated 35 responses with a mean of 14.08 words per question. The majority of responses occurred at the third level as elaborated answers (see Figure 3).

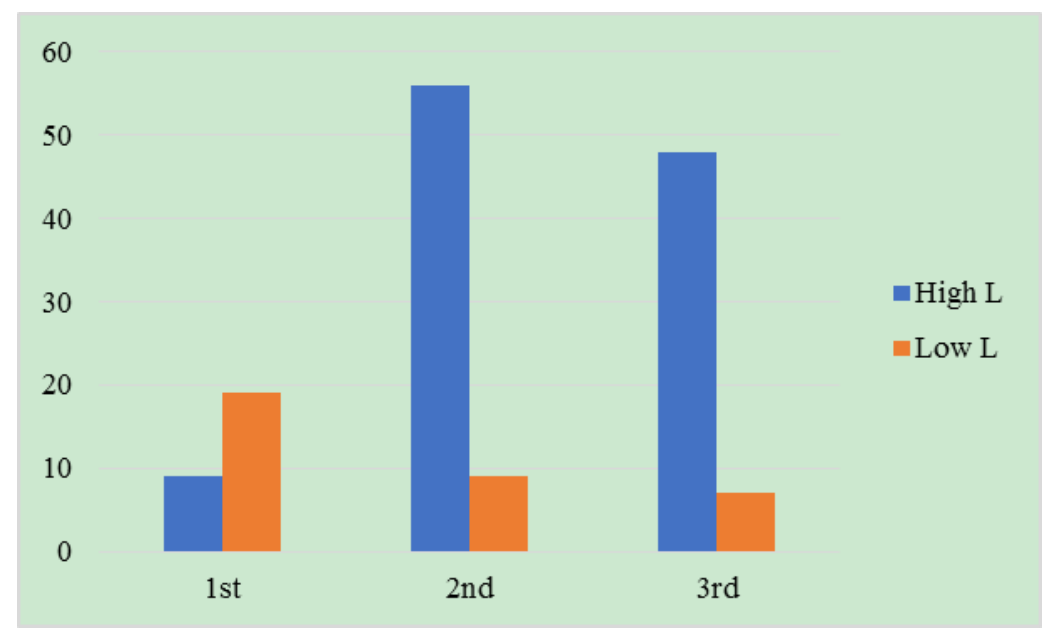

Figure 3. Fluency in students' responses

\subsubsection{Cognitive Level and Student Response: Complexity of the Output}

The complexity of student responses was analysed at the sentence level and classified using Cole and Williams' (1973) classification of responses. Student responses to questions of high cognitive level comprised 108 sentences in 73 responses while the questions of low cognitive level elicited 94 sentences in 35 responses (see Figure 4). Most of the responses to questions of high cognitive level occurred at the first and second levels as phrases and simple sentences. In contrast, most of the responses to low cognitive level questions occurred at the second and third levels as simple, complex and multi sentences. 


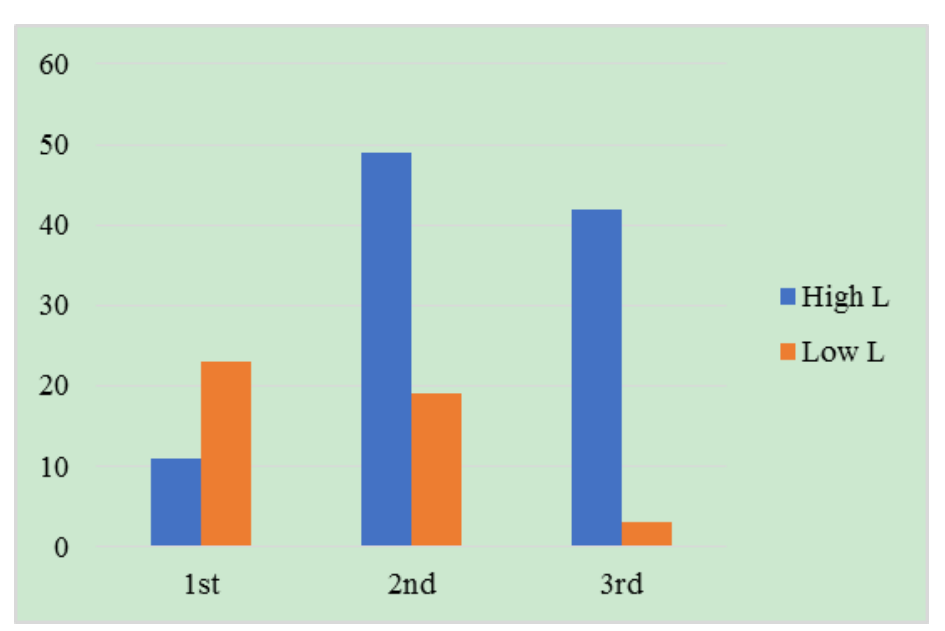

Figure 4. Complexity in students' responses

\section{Discussion}

The study found that instructor questions play a key role in initiating classroom interaction in an online synchronous classroom. The necessity for investigating questions in the synchronous online environment stemmed from the significance of question as a pedagogical tool that can be used to build sustainable interaction in a language classroom (Menayni \& Merabti, 2020; Vuleta \& Martinović 2019; Littleton \& Whitelock, 2004). After analysing five sessions, the researchers identified 93 direct questions used by the instructors. Both instructors asked a question every minute and a half. Hence, question is not only an effective strategy in face-to-face interaction (Heritage \& Heritage, 2013; Beattie and Shovelton, 2002) but also in online synchronous videoconferencing classroom interaction.

This study showed that questions that were of high cognitive level were the most commonly used in this study. This can be attributed to the proficiency level of the native instructors who participated in this study. The current finding concurs with past studies that investigated cognitive level of questions in asynchronous interaction forums (Wang, 2005 and Blanchette, 2001), and face-to-face classroom (Deniz, 2016; Farahian and Rezaee, 2012; Shomoossi, 2004) especially when instructors are native speakers of the language taught. However, the findings of the current study were inconsistent with some other past studies that found that questions of low cognitive level were used more than questions of high cognitive level in traditional classroom lessons (such as Qashoa, 2013; Yang, 2010; Jones et al., 2006; Conteh, 2008; Burns \& Myhill, 2004).

In the current study, the interaction was investigated in relation to classroom participation, fluency and complexity in students' oral production. The results revealed that high cognitive level questions can positively impact whole classroom participation because students were motivated to answer instructors' questions voluntarily. In contrast, low cognitive level questions were answered by one student to which the question was assigned by the instructor. This can be explained by referring to the self-determination theory. Students are usually motivated to participate and engage in any learning activity when they are intrinsically challenged at high cognitive levels (Deci \& Ryan, 1985; Flavell, 1999; Koenigs et al., 1977; 
Niemiec \& Ryan, 2009).

In terms of fluency and complexity, the result shows a negative impact of the use of high cognitive level questions on classroom participation. This finding agrees with several past studies such as Lee (2007) and Wu (1993). This can be explained by referring to the cognitive load theory. The working memory is limited in terms of its capacity and duration while the long-term memory is unlimited. Therefore, tasks with high intrinsic cognitive load in the online environment, which are already attributed to high extraneous load, may impede students from processing and maintaining long and complex responses (Sweller, 2006).

In contrast, low cognitive level questions have a positive impact on students' output. Most of the students' answers were long and complex. This can be attributed to unlimited long-term memory and released working memory. When the students are engaged in online interaction, they could freely retrieve information from their long-term memory without being loaded with a high cognitive level question.

To conclude, question plays a significant role in online interaction. To motivate and engage students successfully we need to trigger students at high cognitive levels. Such questions can encourage high number of learners to answer the initiated question by the teacher. Low cognitive questions, on the other hand, though they help in eliciting long and complex oral production, the number of learners who respond are much less.

The current results stand in contrast to the results from several studies that have been conducted to investigate asynchronous online interaction. In asynchronous interaction students have more time to process and engage in the task assigned by the instructors while in online synchronous interaction students need to generate spontaneous responses. In the latter, the working memory is an important factor that can impede students from generating long and complex answers while in the former the available time can lessen the impact of the load on their working memory. This explains the contrasting results between our study and findings of studies in the literature regarding asynchronous interaction (Sweller et al., 1998, Chandler \& Sweller, 1991, Mayer \& Moreno, 2003; Van \& Sweller, 2005). As a result, low cognitive level questions can help instructors avoid brief responses which are not preferred in any speaking class and use high cognitive level questions which are more effective in generating and motivating students' participation.

\section{Concluding Remarks}

This study investigated instructor questions and their impact on students' oral production in an online synchronous videoconferencing classroom. The study was conducted with Arab and Chinese international EFL students studying English in Malaysia in preparation for their academic study. The students were instructed by two native speakers in an online synchronous speaking class. Questions were classified according to their cognitive level as an important characteristic that can impact classroom participation and interaction in online learning. Regarding the cognitive level of questions, this study found that questions of high cognitive level can motivate and engage students in successful classroom interaction. Questions of low cognitive level, on the other hand, are not able to engage students in 
interaction. In conclusion, the instructors need to be aware of the cognitive level of their own questions and know how to use question types appropriately. If instructors have a clear knowledge of their questions, they can successfully engage their students and elicit more fluent and complex oral production from students. Both represent important factors in building a sustainable pedagogical practice suitable for the online synchronous learning environment.

It is important to acknowledge that the current study has some limitations. First, the number of students and their proficiency level. Second, the study was conducted in an English class with a speaking objective. Hence, it is important to mention that the objective of the class is to motivate students' participation and make students as interactive as possible by using the targeted language. The proficiency level and the size of the class are important factors affecting the choice of questions (Troudi \& Nunan, 1995). Consequently, more studies need to investigate this type of interaction with different student proficiency levels, class sizes, and objectives to possibly reveal more about online interaction and improve students' and instructors' experience in using the online synchronous learning platform.

\section{Authors' declaration}

We declare that this manuscript is original, has not been published before and is not currently being considered for publication elsewhere. We can confirm that the manuscript has been read and approved by all named authors and that there are no other persons who satisfied the criteria for authorship but are not listed. We further confirm that the order of authors listed in the manuscript has been approved by both of us.

\section{References}

Abrami, P. C., Bernard, R. M., Bures, E. M., Borokhovski, E., \& Tamim, R. M. (2011). Interaction in distance education and online learning: Using evidence and theory to improve practice. Journal of Computing in Higher Education, 23(2-3), 82-103. https://doi.org/10.1007/s12528-011-9043-x

AbuBakar, B. S., Paramasivam, S., Lee, G. I., \& Victor Danarajan, S. S. (2021). Interaction in the English language classroom: A review of teacher questions. Malaysian Journal of Social Sciences and Humanities, 6(9), 513-520. https://doi.org/10.47405/mjssh.v6i9.1054

Ahmed, S., \& Alamin, A. (2014). Assessing Speaking Ability in Academic Context for Fourth Year Taif University Students. 4(6), 97-103. https://doi.org/10.5539/ijel.v4n6p97

Altıner, C. (2015). Perceptions of Undergraduate Students about Synchronous Video Conference-based English Courses. Procedia - Social and Behavioral Sciences, 199(4452), 627-633. https://doi.org/10.1016/j.sbspro.2015.07.589

Aydemir, M., Kursun, E., \& Karaman, S. (2016). Question-Answer Activities in Synchronous Virtual Classrooms in Terms of Interest and Usefulness. Open Praxis, 8(1), 9-19. https://doi.org/10.5944/openpraxis.8.1.226

Banna, J., Grace Lin, M.-F., Stewart, M., \& Fialkowski, M. K. (2015). Interaction matters: 
Strategies to promote engaged learning in an online introductory nutrition course. Journal of Online Learning and Teaching, $11(2)$,

249-261. http://www.ncbi.nlm.nih.gov/pubmed/27441032\%0Ahttp://www.pubmedcentral.nih.gov/artic lerender.fcgi?artid=PMC4948751

Beattie, G., \& Shovelton, H. (2002). An experimental investigation of some properties of individual iconic gestures that mediate their communicative power. British Journal of psychology, 93(2), 179-192.

Bernstein, S. P. (2013). A distance education classroom designed to facilitate synchronous learner and instructor interactions (Doctoral dissertation). University of Nebraska, Lincoln, USA.

Blanchette, J. (2001). Questions in the online learning environment. Journal of Distance Education, 16(2), 37-57.

Brock, C. A. (1986). The Effects Questions on of Referential ESL Classroom Discourse. 20(1), 47-59.

Burns, C., \& Myhill, D. (2004). Interactive or inactive? a consideration of the nature of interaction in whole class teaching. Cambridge Journal of Education, 34(1), 35-49. https://doi.org/10.1080/0305764042000183115

Bygate, M., Skehan, P., \& Swain, M. (2001). Researching Pedagogic Tasks: Second Language Learning, Teaching, and Testing. In Routledge (Vol. 4).

Caspi, A., \& Blau, I. (2008). Social presence in online discussion groups: testing three conceptions and their relations to perceived learning. Social Psychology of Education, 11(3), 323-346. https://doi.org/10.1007/s11218-008-9054-2

Chandler, P., \& Sweller, J. (1991). Cognitive Load Theory and the Format of Instruction. Cognition and Instruction, 8(4), 293-332. https://doi.org/10.1207/s1532690xci0804_2

Cole, R. A., \& Williams, D. M. (1973). Pupil Responses to Teacher Questions: Cognitive Level, Length, and Syntax. Educational Leadership Research.

Conteh, J. (2008). Talking, Listening, Learning: effective talk in the primary classroom - by Debra Myhill, Susan Jones and Rosemary Hopper. British Journal of Educational Studies, 56(1), 103-105. https://doi.org/10.1111/j.1467-8527.2008.00397_4.x

Covelli, B. J. (2017). Online Discussion Boards: The Practice of Building Community for Adult Learners. Journal of Continuing Higher Education, 65(2), 139-145. https://doi.org/10.1080/07377363.2017.1274616

Deci, E. L., \& Ryan, R. M. (1985). The general causality orientations scale: Self-determination in personality. Journal of Research in Personality, 19(2), 109-134. https://doi.org/10.1016/0092-6566(85)90023-6

Deniz Yilmaz, S. (2016). İngilizceyi YabanciDil Olarak Öğrenen SiniflardSözdizimsel Olarak Farkli OlanTeşhir Ve Göndergesel Sorularin Öğrenci CevaplarÜzerindekiEtkisi. International 
Journal of Language Academy, 4(10), 315-315. https://doi.org/10.18033/ijla.376

Durairaj, K., \& Umar, I. N. (2015). A Proposed Conceptual Framework in Measuring Social Interaction and Knowledge Construction Level in Asynchronous Forum among University Students. Procedia - Social and Behavioral Sciences, 176, 451-457. https://doi.org/10.1016/j.sbspro.2015.01.496

Ertmer, P. A., Ertmer, D., \& Sadaf, A. (2011). Designing Effective Question Prompts to Facilitate Critical Thinking in Online Discussions. Design Principles and Practices: An International Journal-Annual Review, $\quad$ 5(4), https://doi.org/10.18848/1833-1874/cgp/v05i04/38121

Farahian, M., \& Rezaee, M. (2012). A case study of an EFL teacher's type of questions: an $\begin{array}{llll}\text { investigation into classroom interaction. } & \text { 161-167. }\end{array}$ https://doi.org/10.1016/j.sbspro.2012.06.631

Fei, T., Heng, W. J., Toh, K. C., \& Qi, T. (2003). Question classification for e-learning by artificial neural network. ICICS-PCM 2003 - Proceedings of the 2003 Joint Conference of the 4th International Conference on Information, Communications and Signal Processing and 4th Pacific-Rim Conference on Multimedia, 3, 1757-1761. https://doi.org/10.1109/ICICS.2003.1292768

Flavell, J. H. (1999). Cognitive development: Children's knowledge about the mind. Annual Review of Psychology, 50, 21-45. https://doi.org/10.1146/annurev.psych.50.1.21

Gall, M. D. (1970). The use of questions in teaching. Review of Educational Research, 40(5), 707-721. https://doi.org/10.3102/00346543040005707

Glance, D. G., Forsey, M., \& Riley, M. (2013). The Pedagogical Foundations of Massive Open Online Courses. First Monday.

Goossen, L. H. (2002). Classroom questioning strategies as indicators of inquiry-based science instruction (Doctoral dissertation). Western Michigan University, Kalamazoo, Michigan.

Greene, J. C. (2003). Handbook of communication and social interaction skills. Psychology Press.

Heritage, M., \& Heritage, J. (2013). Applied Measurement in Education Teacher Questioning: The Epicenter of Instruction and Assessment Teacher Questioning: The Epicenter of Instruction and Assessment. March 37-41. https://doi.org/10.1080/08957347.2013.793190

Herring, S. C. (2004). Computer-mediated discourse analysis: An approach to researching online behavior. In Designing for Virtual Communities in the Service of Learning (Issue March). https://doi.org/10.1017/CBO9780511805080.016

Inoue, A., \& Zhang, Y. (2011). Replication-Dependent Loss of 5-Hydroxymethylcytosine in Mouse Preimplantation Embryos. Science, 334(6053), 194 LP - 194. 
https://doi.org/10.1126/science.1212483

Iwashita, N., McNamara, T., \& Elder, C. (2001). Can We Predict Task Difficulty in an Oral Proficiency Test? Exploring the Potential of an Information-Processing Approach to Task Design. Language Learning, 51(3), 401-436. https://doi.org/10.1111/0023-8333.00160

Jones, R. H., Garralda, A., Li, D. C. S., \& Lock, G. (2006). Interactional dynamics in on-line and face-to-face peer-tutoring sessions for second language writers. Journal of Second Language Writing, 15(1), 1-23. https://doi.org/10.1016/j.jslw.2005.12.001

Kauffman, H. (2015). A review of predictive factors of student success in and satisfaction with online learning. Research in Learning Technology, 23(1063519), 1-13. https://doi.org/10.3402/rlt.v23.26507

Kock, N. (2005). Media richness or media naturalness? The evolution of our biological communication apparatus and its influence on our behavior toward e-communication tools. IEEE Transactions on Professional Communication, 48(2), 117-130. https://doi.org/10.1109/TPC.2005.849649

Koenigs, S. S., Fiedler, M. L., \& DeCharms, R. (1977). Teacher beliefs, classroom interaction and personal causation. In Journal of Applied Social Psychology (Vol. 7, Issue 2, pp. 95-114). Blackwell Publishing. https://doi.org/10.1111/j.1559-1816.1977.tb01332.x

Lee, Y. A. (2007). Third turn position in teacher talk: Contingency and the work of teaching. Journal of Pragmatics, 39(1), 180-206. https://doi.org/10.1016/j.pragma.2006.02.004

Levin, J., \& Nolan, J. F. (2004). Principles of classroom management: A professional decision making model (4th ed.). New York, NY:Allyn \& Bacon.

Lindenmeyer, S. (1990). Study of referential and display questions and their responses in adult ESL reading classes. Dissertations and Theses. Paper 4070. https://doi.org/10.15760/etd.5954

Littleton, K., \& Whitelock, D. (2004). Guiding the Creation of Knowledge and Understanding in a Virtual Learning Environment. Cyberpsychology and Behavior, 7(2), 173-181. https://doi.org/10.1089/109493104323024438

Mayer, R. E., \& Moreno, R. (2003). Nine Ways to Reduce Cognitive Load in Multimedia Learning. Educational Psychologist, $\quad$ 38(1), https://doi.org/10.1207/S15326985EP3801_6

Mehnert, U. (1998). the Effects of Different Lengths of Time for Planning on Second Language Performance. Studies in Second Language Acquisition, 20(1), 83-108. https://doi.org/10.1017/s0272263198001041

Menayni, N., \& Merabti, M. (2020). Teachers' Perceptions of the Effect of Question-Asking Behaviour on EFL Classroom Interaction. International Journal of Language and Literary Studies, 2(1), 234-253.

Mirza, C. (2014). Multimedia Online Interactions in Audio-Graphic Conferencing Systems : 
the Case of Adult Distance. The Open University's Repository of Research Publications and Other Research Outputs.

Newcomb L. R., \& Trefz, M. K. (1987, February). Levels of Cognition of Student Tests and Assignments in The College of Agriculture at The Ohio State University. Proceedings of The Central Region 41st Annual Research Conference in Agricultural Education, Qiicago, 1L.

Niemiec, C. P., \& Ryan, R. M. (2009). Autonomy, competence, and relatedness in the classroom: Applying self-determination theory to educational practice. Theory and Research in Education, 7(2), 133-144. https://doi.org/10.1177/1477878509104318

O’Rourke, B., \& Stickler, U. (2017). Synchronous communication technologies for language learning: Promise and challenges in research and pedagogy. Language Learning in Higher Education, 7(1), 1-20.

Palomeque, C., \& Pujolà, J. T. (2018). Managing multimodal data in virtual world research for language learning. ReCALL, 30(2), 177-195. https://doi.org/10.1017/S0958344017000374

Parker, M., \& Hurry, J. (2007). Teachers' use of questioning and modelling comprehension skills in primary classrooms. Educational Review, 59(3), 299-314. https://doi.org/10.1080/00131910701427298

Portocarrero, S., Burright, R. G., \& Donovick, P. J. (2007). Vocabulary and verbal fluency of bilingual and monolingual college students. 22, 415-422. https://doi.org/10.1016/j.acn.2007.01.015

Qashoa, S. (2013). Effects of teacher question types and syntactic structures on EFL classroom interaction. The International Journal of Social Sciences, 7(1), 52-62.

Robinson, P. (2007). Task complexity, theory of mind, and intentional reasoning: Effects on L2 speech production, interaction, uptake and perceptions of task difficulty. IRAL International Review of Applied Linguistics in Language Teaching, 45(3), 193-213. https://doi.org/10.1515/iral.2007.009

Rojas-Drummond, S. M., Albarrán, C. D., \& Littleton, K. S. (2008). Collaboration, creativity and the co-construction of oral and written texts. Thinking Skills and Creativity, 3(3), 177-191. https://doi.org/10.1016/j.tsc.2008.09.008

Shantha, S., \& Mekala, S. (2018). The Impact of Pedagogical Intervention in Developing the Speaking Proficiency of Engineering Students. Social Sciences \& Humanities, 26(2), 735-750.

Shomoossi, N. (2004). The effects of Teachers' Questioning Behaviour on EFL Classroom Interaction: A Classroom Reseacrh Study. The Reading Matrix, 4(2), 96-104.

Sun, P. C., \& Cheng, H. K. (2007). The design of instructional multimedia in e-Learning: A Media Richness Theory-based approach. Computers and Education, 49(3), 662-676. https://doi.org/10.1016/j.compedu.2005.11.016

Swain, M. (1985). Communicative competence: Some roles of comprehensible input and 
comprehensible output in its development. In S. M. Gass, \& C. Madden (Eds.), Input in second language acquisition (pp. 235-253). Rowley, Mass: Newbury House.

Sweller, J. (1994). Cognitive load theory, learning difficulty, and instructional design. Learning and instruction, 4(4), 295-312.

Sweller, J. (2006). The worked example effect and human cognition. In Learning and Instruction (Vol. 16, Issue 2, pp. 165-169). Elsevier Science. https://doi.org/10.1016/j.learninstruc.2006.02.005

Sweller, J., Van Merrienboer, J. J. G., \& Paas, F. G. W. C. (1998). Cognitive Architecture and Instructional Design. Educational Psychology Review, 10(3), 251-296. https://doi.org/10.1023/A:1022193728205

Terras, K. L. (2017). Transforming the Teacher: Examining Personal Transformations of Faculty Redesigning Courses from Face-to-Face to Online. Journal of Transformative Learning, 1(4), 33-49.

Thai, C., \& Boers, F. (2016). Repeating a Monologue Under Increasing Time Pressure: Effects on Fluency, Complexity, and Accuracy. TESOL Quarterly, 50(2), 369-393. https://doi.org/10.1002/tesq.232

Troudi, S., \& Nunan, D. (1995). Research Methods in Language Learning. TESOL Quarterly, 29(3), 601. https://doi.org/10.2307/3588081

Van Merriënboer, J. J. G., \& Sweller, J. (2005). Cognitive load theory and complex learning: Recent developments and future directions. In Educational Psychology Review (Vol. 17, Issue 2). https://doi.org/10.1007/s10648-005-3951-0

Vuleta, K., \& Martinović, A. (2019). Teacher questions in EFL classrooms. Metodički ogledi: časopis za filozofiju odgoja, 26(1), 149-175.

Wang, C. H. (2005). Questioning skills facilitate online synchronous discussions. Journal of Computer Assisted Learning, 303-313. https://doi.org/10.1111/j.1365-2729.2005.00138.x

Weiser, O., Blau, I., \& Eshet-Alkalai, Y. (2018). How do medium naturalness, teaching-learning interactions and Students' personality traits affect participation in synchronous E-learning?. Internet and Higher Education, 37(September 2017), 40-51. https://doi.org/10.1016/j.iheduc.2018.01.001

Wright, B. M. (2016). Display and referential questions: Effects on student responses. NJES Nordic Journal of English Studies, 15(4), 160-189. https://doi.org/10.35360/njes.388

Wu, K. Y. (1993). Classroom Interaction and Teacher Questions Revisited. RELC Journal, 24(2), 49-68. https://doi.org/10.1177/003368829302400203

Yang, C. C. R. (2010). Teacher Questions in Second Language Classrooms: An Investigation of Three Case Studies. Asian EFL Journal, 12(1). 


\section{Macrothink}

International Journal of Linguistics

ISSN 1948-5425 2021, Vol. 13, No. 6

Zhou, N., Kisselburgh, L., Chandrasegaran, S., Badam, S. K., Elmqvist, N., \& Ramani, K. (2020). Using social interaction trace data and context to predict collaboration quality and creative fluency in collaborative design learning environments. International Journal of $\begin{array}{llll}\text { Human } \quad \text { Computer } & \text { Studies, } & \text { 136(January }\end{array}$ https://doi.org/10.1016/j.ijhcs.2019.102378

\section{Copyrights}

Copyright for this article is retained by the author(s), with first publication rights granted to the journal.

This is an open-access article distributed under the terms and conditions of the Creative Commons Attribution license (http://creativecommons.org/licenses/by/4.0/) 